\title{
Cluster analysis of acoustic emission signals for 2D and 3D woven carbon fiber/epoxy composites
}

\author{
Li Li ${ }^{\mathrm{a}, \mathrm{b},{ }^{*}}$, Yentl Swolfs ${ }^{\mathrm{b}}$, Ilya Straumit ${ }^{\mathrm{b}}$, Xiong Yan ${ }^{\mathrm{a}}$, Stepan V. Lomov ${ }^{\mathrm{b}}$

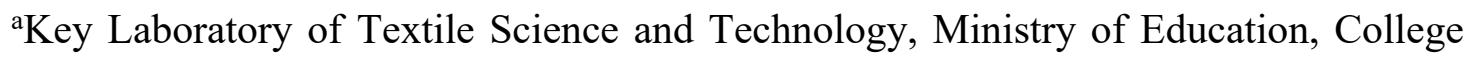 \\ of Textiles, Donghua University, Shanghai 201600, China \\ ${ }^{b}$ Department of Materials Engineering, KU Leuven, Kasteelpark Arenberg 44, B-3001 \\ Leuven, Belgium \\ *Corresponding author: lililainey@gmail.com
}

\begin{abstract}
Understanding the failure mechanisms in textile composites based on acoustic emission (AE) signals is a challenging task. In the present work, unsupervised cluster analysis is performed on the $\mathrm{AE}$ data registered during tensile tests on $2 \mathrm{D}$ and $3 \mathrm{D}$ woven carbon fiber/epoxy composites. The analysis is based on the k-means++ algorithm and principal component analysis. Peak amplitude and frequency features peak frequency for $2 \mathrm{D}$ woven composites and frequency centroid for $3 \mathrm{D}$ woven composites - were found to be dominant in cluster analysis. Cluster bounds were identified for both reinforcement types. These bounds do not differ for both reinforcement types and can be used as a starting point for AE analysis of other carbon fiber/epoxy composites. The statistics of high frequency AE events are compared with the estimates obtained from a fiber bundle model based on Weibull fiber strength statistics. The number of AE events agrees well with the number of groups of carbon fibers that fail simultaneously. This finding may provide a new way to explain why the Weibull distribution predicts much more fiber breaks than measured by AE.
\end{abstract}

Keywords: A. Polymer-matrix composites; A. 3-Dimensional reinforcement; A. Carbon fiber; D. Acoustic emission

\section{Introduction}

Acoustic emission (AE) registration is an important non-destructive technique for detecting and identifying damage development in fiber-reinforced composites ${ }^{1-7}$. The $\mathrm{AE}$ technique has been extensively applied to carbon fiber reinforced polymers $(\mathrm{CFRP})^{1-5}$, allowing identification of damage initiation and propagation during loading. A crucial but unresolved problem is the development of methods for identifying damage modes based on the parameters of $\mathrm{AE}$ events, such as amplitude, frequency and signal rise time. The evolution of cumulative energy of AE events has been used for identifying damage initiation and propagation thresholds in textile composites ${ }^{3,4,8}$. However, this approach does not allow identification of the damage modes associated with the AE events. 
Cluster analysis is a powerful methodology to analyze multi-parametrical AE signals ${ }^{9-}$ 11. This analysis classifies events based on clustering of their multi-parametrical descriptors. This hence creates a framework for subsequent identification of the links between the established cluster event classification and the physical nature of the damage.

Classifications of AE events based on amplitude have been performed in the past for unidirectional and cross-ply CFRP laminates ${ }^{12,13}$. Peak amplitude alone does not seem to be a reliable parameter to distinguish damage mechanisms. Valentin et al. ${ }^{12}$ and Liu et al. ${ }^{13}$ concluded that matrix cracking was associated with low amplitude signals, fiber-matrix debonding with medium amplitude events, and fiber failure with high amplitude events. This classification contradicts the one proposed by Berthelot et al. ${ }^{14}$, which suggests that high amplitude signals correspond to matrix cracking, while low amplitude signals correspond to fiber breakage.

Cluster analysis based on both time and frequency features showed that the peak frequency of an AE signal can represent specific damage mechanisms ${ }^{11,15}$. The low frequency range is normally attributed to matrix cracking, while high frequency is attributed to fiber breakage. In contrast, the frequency range for delamination and fiber-matrix debonding varies in different studies. De Groot et al. ${ }^{15}$ and Gutkin et al. ${ }^{11}$ investigated carbon/epoxy laminates in different tests and obtained similar frequency bands for the fiber-matrix debonding (medium frequency range from 200 to $300 \mathrm{kHz}$ ) and fiber breakage (high frequency over $300 \mathrm{kHz}$ ). However, these authors mention different frequency ranges for the other damage modes. Matrix cracking was related to the $50-180 \mathrm{kHz}$ frequency range in De Groot et al. ${ }^{15}$, whereas this range was below 50 $\mathrm{kHz}$ in Gutkin et al. ${ }^{11}$. Fiber pull-out corresponded to frequencies around $200 \mathrm{kHz}$ in De Groot et al. ${ }^{15}$ but to frequencies above $500 \mathrm{kHz}$ in Gutkin et al. ${ }^{11}$. Delaminationrelated $\mathrm{AE}$ events corresponded to a higher frequency range: from 220 to $300 \mathrm{kHz}$ in De Groot et al. ${ }^{15}$, compared to 50 to $150 \mathrm{kHz}$ in Gutkin et al. ${ }^{11}$.

Sause et al. ${ }^{10}$ identified clusters of AE signals for unidirectional glass fiber reinforced polymers (GFRP) and CFRP composites using the approach proposed in literature9. They found that frequency features can help to distinguish between matrix cracking, interfacial failure and fiber breakage. Accumulated AE signal amplitudes also reflected the extent of the damage, while the frequency feature identified the damage mechanism ${ }^{10}$. The works cited above all deal with unidirectional or $2 \mathrm{D}$ woven laminates. Cluster analysis of AE signals applied to 3D woven CFRP has not been performed yet.

In our previous study ${ }^{5}$, the applicability of the AE frequency bands proposed in literature $^{11,15}$ was investigated for $3 \mathrm{D}$ carbon/epoxy non-crimp woven composites. The number of high frequency AE events was found to be inconsistent with the number of fiber breaks predicted from simple Weibull statistics for fiber strength. However, the findings in literature ${ }^{5}$ are not fully conclusive for three reasons. Firstly, the observed inconsistency was supposedly attributed to the presence of random individual fiber waviness within the yarns. This can change the fiber breakage conditions, but was not further investigated. Secondly, the statistics of multiple fiber 
breakage were not considered. Thirdly, the authors did not perform a full cluster analysis, and may not have been able to fully distinguish all AE signals.

The present paper deals with these deficiencies. A cluster analysis is performed on the measurements in literature ${ }^{3,4}$. The analysis of the fiber breakage statistics is extended to include fiber misalignment and collective fiber breakage ${ }^{16-20}$. The AE analysis methodology that was previously used for 2D and 3D glass/epoxy woven composites ${ }^{21}$, is now applied to $2 \mathrm{D}$ and $3 \mathrm{D}$ carbon fiber-reinforced woven composites ${ }^{3,4}$. The internal architecture of these reinforcements is comparable to that of their glass fiber counterparts in literature ${ }^{21}$. This study has two objectives. The first objective is to find out whether AE events in carbon/epoxy woven composites can be represented with the same cluster construction as for their glass/epoxy counterparts. This includes establishing generic cluster bounds for $2 \mathrm{D}$ and $3 \mathrm{D}$ composites, as was done for glass/epoxy composites in literature ${ }^{21}$. The second objective is to refine the statistics of fiber breakage in 2D and 3D woven composites based on more detailed analysis compared to literature ${ }^{5}$. This analysis investigates the influence of fiber misalignment and collective fiber breakage in fiber bundles. Comparing the fiber break statistics with the high frequency clusters provides additional grounds for identifying these clusters with fiber breakage.

Signal attenuation and wave propagation in general (for example, the specimen transfer function) can have an influence on the damage identification, but these effects were not studied by us. In a recent paper [22] these effects are investigated in detail and will be an important component of AE analysis in the future work.

\section{Materials and methods}

\subsection{Materials and test methods}

The materials used in this study are carbon fiber/epoxy composites based on balanced 2D twill $2 / 2$ and 3D non-crimp orthogonal woven composites, which were manufactured by resin transfer molding and vacuum assisted resin infiltration. This was performed at a vacuum pressure of $\sim 0.1 \mathrm{MPa}$ in the similar condition and have similar fiber volume fraction and thickness. Their internal structure, experimental procedure and mechanical behavior were previously described in detail ${ }^{3,4}$. The structure and properties of the preforms and composites are shown in Fig. 1 and Table $1^{3,4}$. Fig 1 also shows typical crack patterns in the studied materials. Tensile tests were performed according to ASTM D3039 standard. All specimens were $250 \mathrm{~mm}$ long with a gauge length of $170 \mathrm{~mm}$. The nominal width of the 2D and 3D specimens was $25 \mathrm{~mm}$ and 31 $\mathrm{mm}$, respectively. The surface strain was measured using a digital image correlation system. The 2D twill specimens were tested only in the warp direction, as the weave was balanced. The 3D specimens were tested both in warp and fill direction, as this weave was not balanced. The reader can refer to literature ${ }^{3,4}$ for detailed information on the materials, specimens and test methods, as well as for detailed description of the damage development, including images of the cracks. 

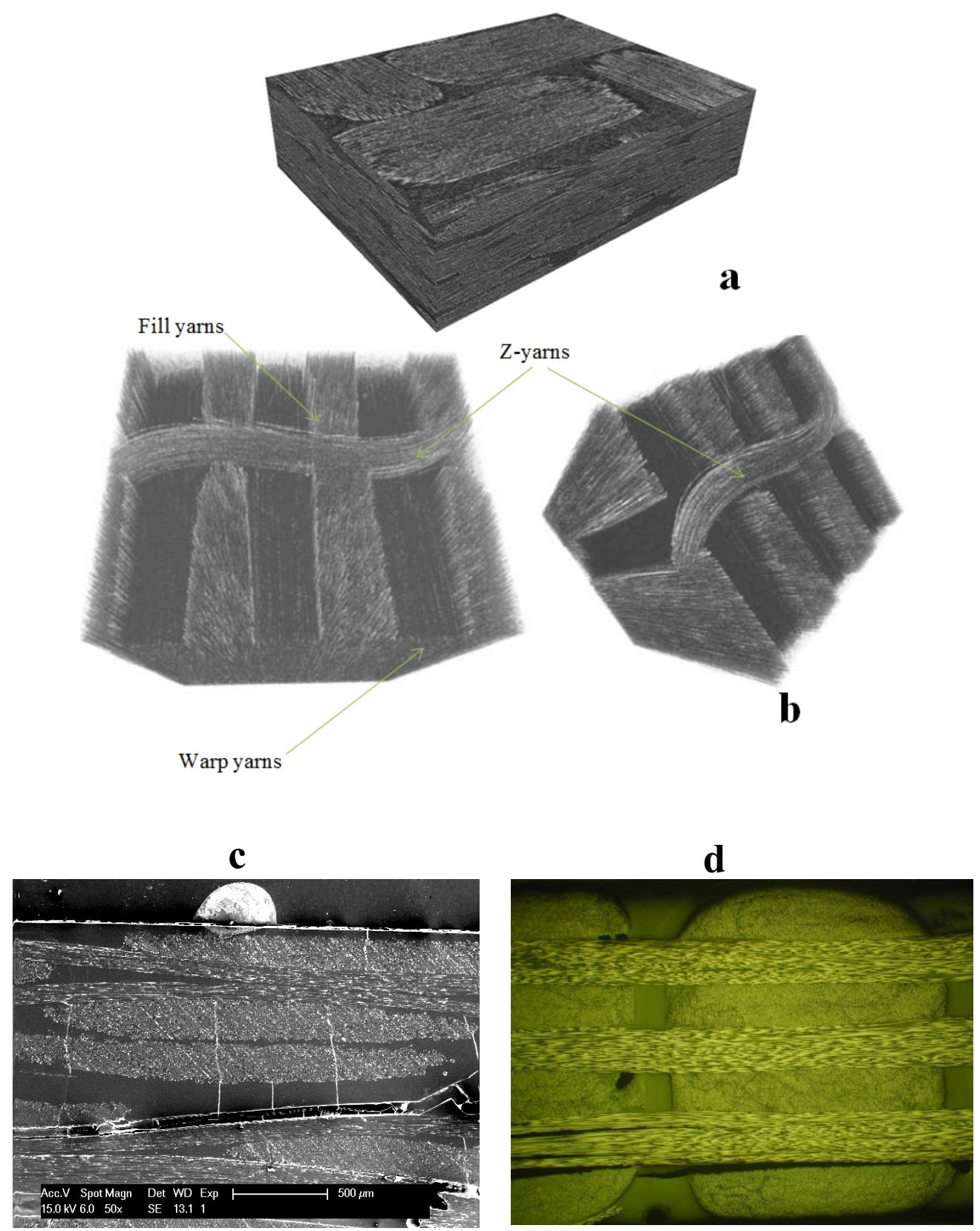

Fig. 1: MicroCT images of the reinforcement architecture of (a) the 2D twill 2/2 woven fabric ${ }^{3}$, and (b) the 3D non-crimp orthogonal woven fabric ${ }^{4,5}$, and typical crack patterns in the 2D (c) and 3D (d) specimens under warp-direction loading.

Table 1: Properties of the preforms and the carbon/epoxy composites: $2 D^{3}$ and $3 D^{4}$.

\begin{tabular}{llcc}
\hline & & 3D non-crimp & 2D twill 2/2 \\
\hline & Fabric plies & 1 & 7 (warp direction \\
in all plies coincides)
\end{tabular}




\begin{tabular}{|c|c|c|c|c|}
\hline \multirow[t]{6}{*}{ Preforms } & & Fiber volume fraction $(\%)$ & 46,12 & \\
\hline & Fill & Insertion density (picks/cm) & 3.91 & 3,5 \\
\hline & & Carbon yarn & $\begin{array}{c}\text { Toho Tenax } 12 \mathrm{~K}, 800 \\
\text { tex }\end{array}$ & AS4C GP $6 \mathrm{~K}, 400$ tex \\
\hline & & Fiber volume ratio (\%) & 51,24 & - \\
\hline & Z yarns & Yarns (tex) & Toho Tenax $1 \mathrm{~K}, 66$ tex & - \\
\hline & & Fiber volume ratio (\%) & 2.64 & \\
\hline \multirow{3}{*}{ Composites } & & Fiber volume fraction (\%) & 51.1 & 55.2 \\
\hline & & Thickness(mm) & 2.76 & 2.14 \\
\hline & & Resin & $\begin{array}{c}\text { Epikote } 828 \text { LVEL } \\
\text { hardener: Dytek DCH-99 }\end{array}$ & $\begin{array}{l}\text { West System } 105 \\
\text { epoxy } \\
\text { hardener: } 209 \text { Extra } \\
\text { Slow Hardener }\end{array}$ \\
\hline
\end{tabular}

The AE events were monitored by Vallen AMSY-5 system with the sensors being 120 $\mathrm{mm}$ apart. The preamplifier used was AEP4 with threshold $34 \mathrm{~dB}$. The transducers used were Digital Wave B-1025 and it can be used in a temperature range of $-50{ }^{\circ} \mathrm{C}$ to $100{ }^{\circ} \mathrm{C}^{4,5}$. The transfer function of this sensor is illustrated in Fig. $2^{23}$. The acquisition parameters are summarized in Table $2^{3,4}$. The linear location is used in this study from two sensors mounted on the tensile specimens, and calculated by Vallen AE software. The AE data of 2D and 3D carbon/epoxy woven specimens recorded in the previously reported experiments ${ }^{3,4}$ was employed in this work. Previous studies have identified the following damage types during the tensile loading by optical microscopy ${ }^{3-5}$ :

- for the 2D woven composites: matrix cracking, including transverse and later longitudinal cracks in the yarns, and local delamination;

- for the 3D woven composites: cracks in the z-yarns and at its boundaries as well as transverse and longitudinal cracks ${ }^{4,5}$.

The cluster analysis of AE events should reflect the differences between these damage types and discriminate between them. Three tests for each specimen type were chosen for cluster analysis in this study. The specimens are referred to as 2D-n, 3DW-n, 3DF$\mathrm{n}$, where ' $2 \mathrm{D}$ ' and ' $3 \mathrm{D}$ ' indicates the type of preform, ' $\mathrm{W}$ ' and ' $\mathrm{F}$ ' indicates the warp and fill direction for 3D composites respectively, and $n=1,2,3$ is the specimen number.

Table 2: Data acquisition parameters of the acoustic emission test ${ }^{3-5}$.

\begin{tabular}{lc}
\hline Software & Vallen AMSY-5 \\
Amplifiers & Vallen AEP4 \\
Amplification, dB & 34 \\
Discrimination time, & 0.4 \\
Rearm time, ms & 3.2 \\
Range, $\mathrm{MHz}$ & $0.025-1.6$ \\
Sample rate, $\mathrm{MHz}$ & 5 \\
\hline
\end{tabular}




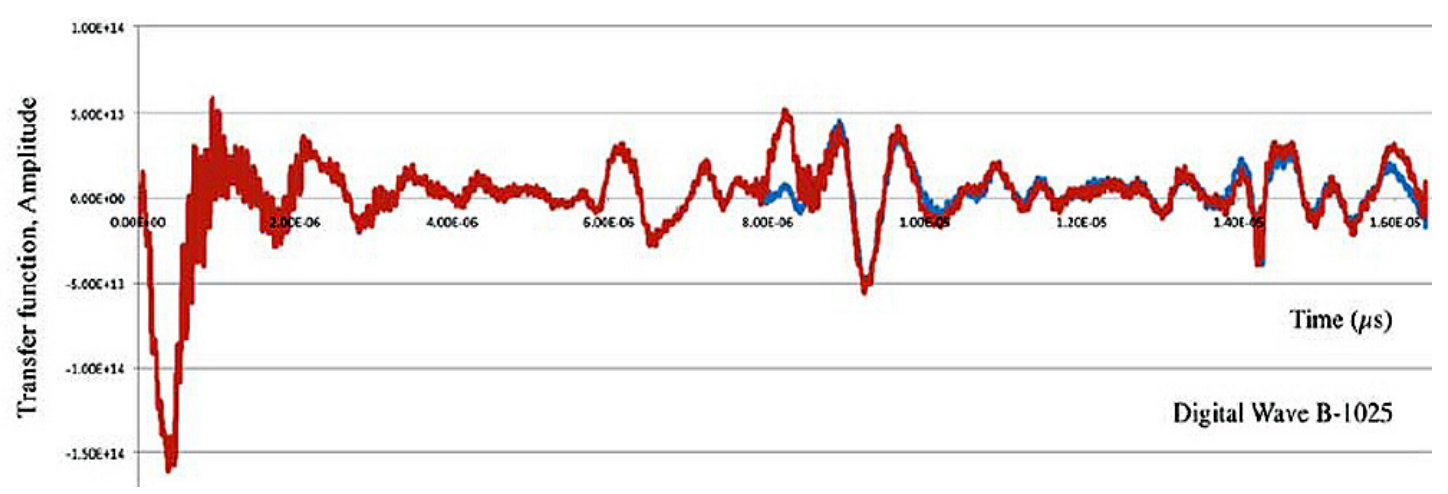

Fig. 2: Transfer function of Digital Wave B-1025 sensor $^{23}$.

\subsection{Cluster analysis methods}

The same cluster analysis was performed on AE events of 2D and 3D carbon/epoxy composites as it was performed for 2D and 3D glass/epoxy composites. The details of the employed analysis can be found in literature ${ }^{21}$. The carbon/epoxy composites studied here, have the same 3D weave pattern as the glass/epoxy composites in literature ${ }^{21}$.

Nine AE signal features were considered in this paper, which are signal peak amplitude, duration, rise time, energy, counts, RA value, peak frequency, frequency centroid and weighted frequency. The definition of time domain parameters peak amplitude, duration, rise time and counts are presented in Fig. 3a. Peak frequency is the component of the signal frequency spectrum with the highest Fast Fourier transform magnitude. The frequency centroid of gravity, or frequency centroid, is defined as:

$F_{C o G}=\frac{\int f \cdot A(f) d f}{\int A(f) d f}$,

where $f$ is the frequency in the spectrum, $A(f)$ is the magnitude of the corresponding frequency from the Fourier transformation of the signal, with unit $\mathrm{mV}^{9}$. The definition of these two frequency parameters is illustrated in Fig. $3 \mathrm{~b}$. 

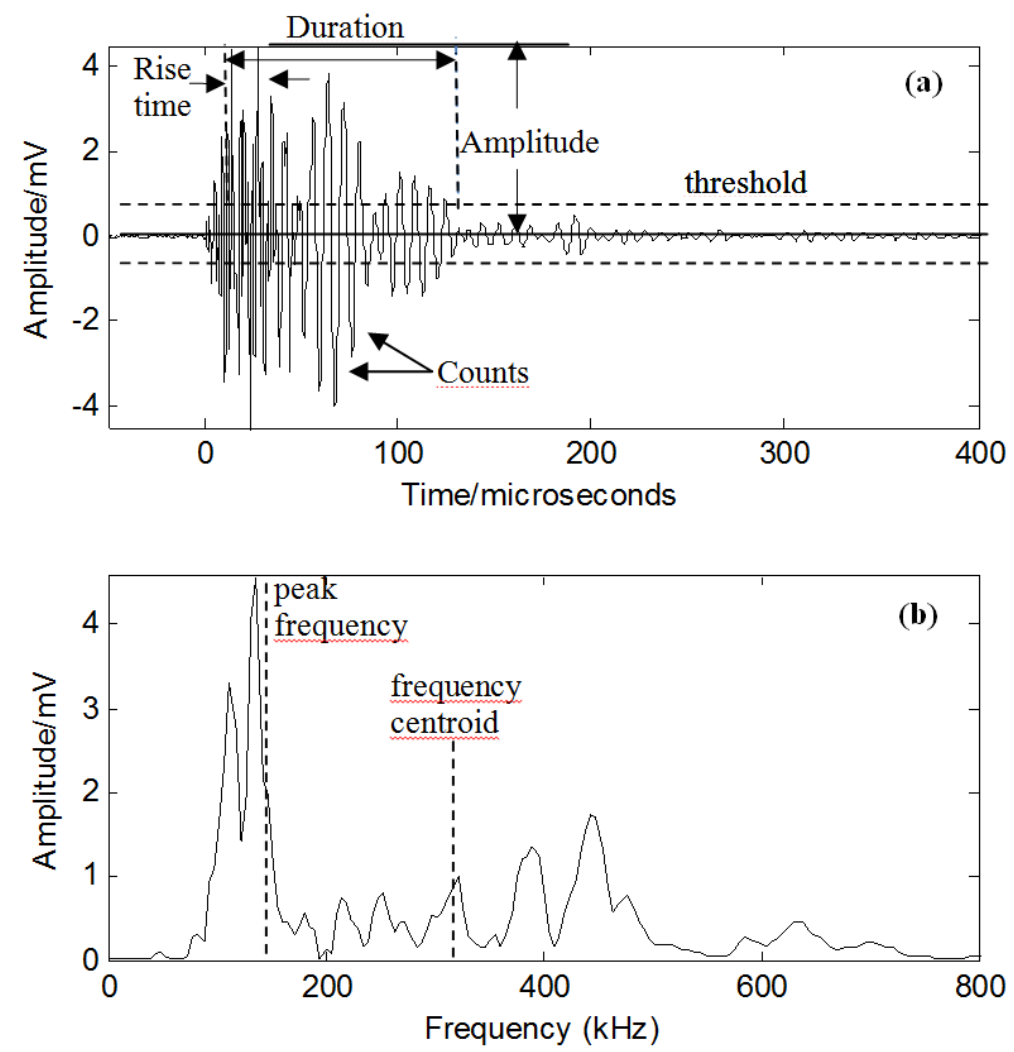

Fig. 3: The spectrum of a typical AE signal: (a) time domain, (b) frequency spectrum after Fast Fourier Transform, and AE frequency features - peak frequency and frequency centroid.

Four parameters were chosen as $\mathrm{AE}$ descriptors out of these nine $\mathrm{AE}$ features by feature selection procedure. This procedure is based on the so-called Laplacian score ${ }^{24}$, which is based on the proximity of the data classes in a multi-parametrical space. This score has also been used in literature ${ }^{21}$. It ranges between 0 and 1 , where a larger score indicates a higher cluster ability of the investigated feature. This procedure deduced four AE parameters that should be used in the cluster analysis: peak amplitude (PA), peak frequency $(\mathrm{PF})$, rise time divided by peak amplitude (RA value) and frequency centroid of gravity (FCoG).

Principal Component Analysis (PCA) and k-means++ algorithm were used to cluster the AE events. The Silhouette Coefficient (SC) and Davies-Bouldin index (DB) were used to evaluate the cluster validity, with a higher SC and lower DB indicating better cluster quality. The reader can refer to $\mathrm{Li}$ et al. ${ }^{21}$ for the details of the employed algorithms. The cluster analysis is performed using the Statistics toolbox in MatLab R2013a.

\section{Cluster analysis results and discussion}

\subsection{Repeatability of $A E$ registration}

Before performing the cluster analysis, the repeatability of the AE events for different tests was investigated to ensure consistency of the AE data. Fig. 4 shows the AE 
energy as a function of the applied strain for all individual tests on the 2D and 3D specimens. Fig. 5 represents the peak amplitude and peak frequency distribution for all the tests. For all the 2D and 3D woven composites, the peak amplitude distribution and peak frequency distribution follow a similar pattern. They have fewer events in the amplitude range over $55 \mathrm{~dB}$ and frequency range over $65 \mathrm{kHz}$, compared to the low amplitude and the low frequency range. It can be concluded from the data in Fig. 4 and Fig. 5 that the repeatability of AE registration is satisfactory and that cluster analysis can be performed with confidence.
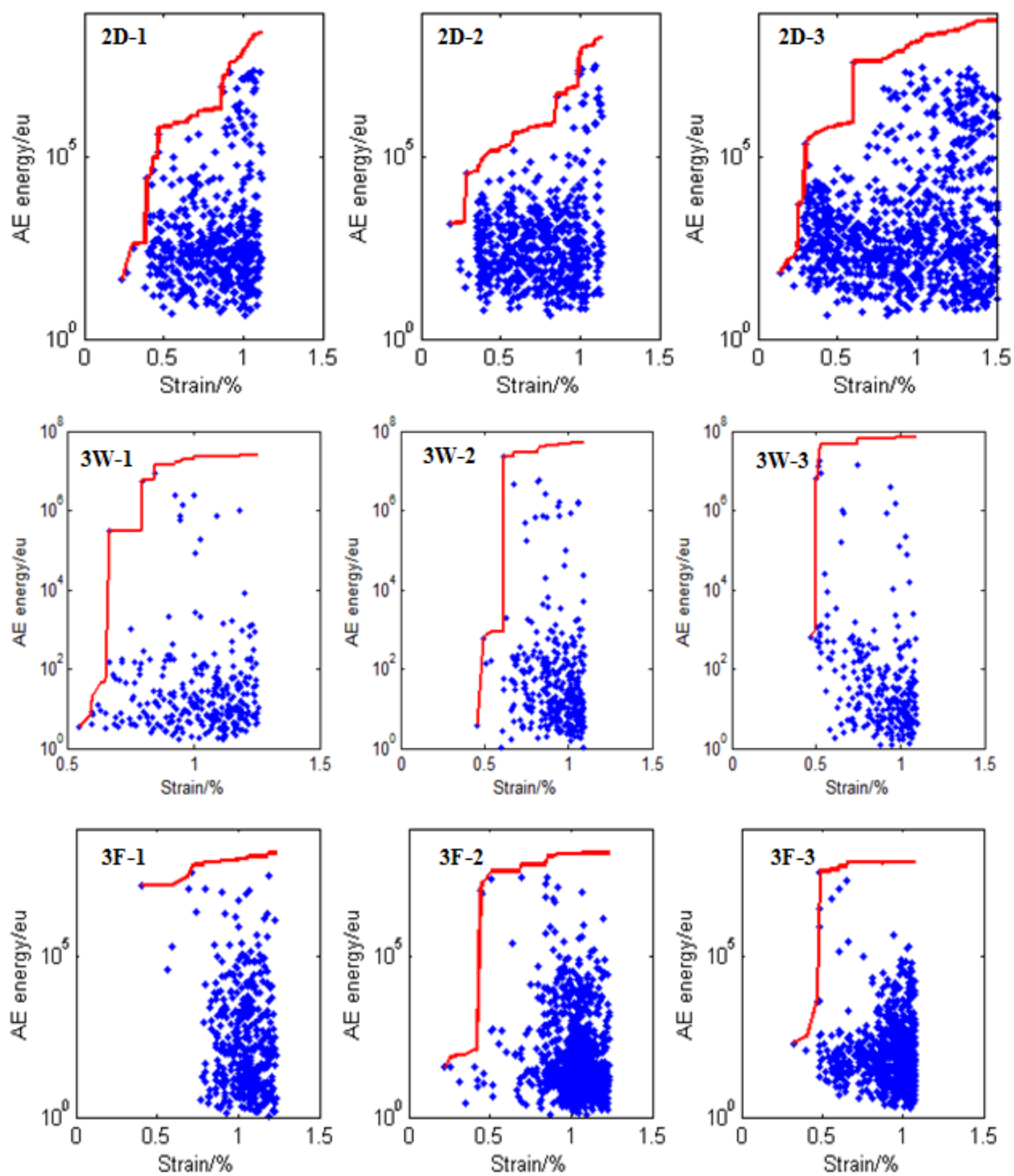

Fig. 4: AE event patterns for all 2D and 3D individual tests. Blue dots represent the energy of AE events, while the red line represents the cumulative $\mathrm{AE}$ energy. 

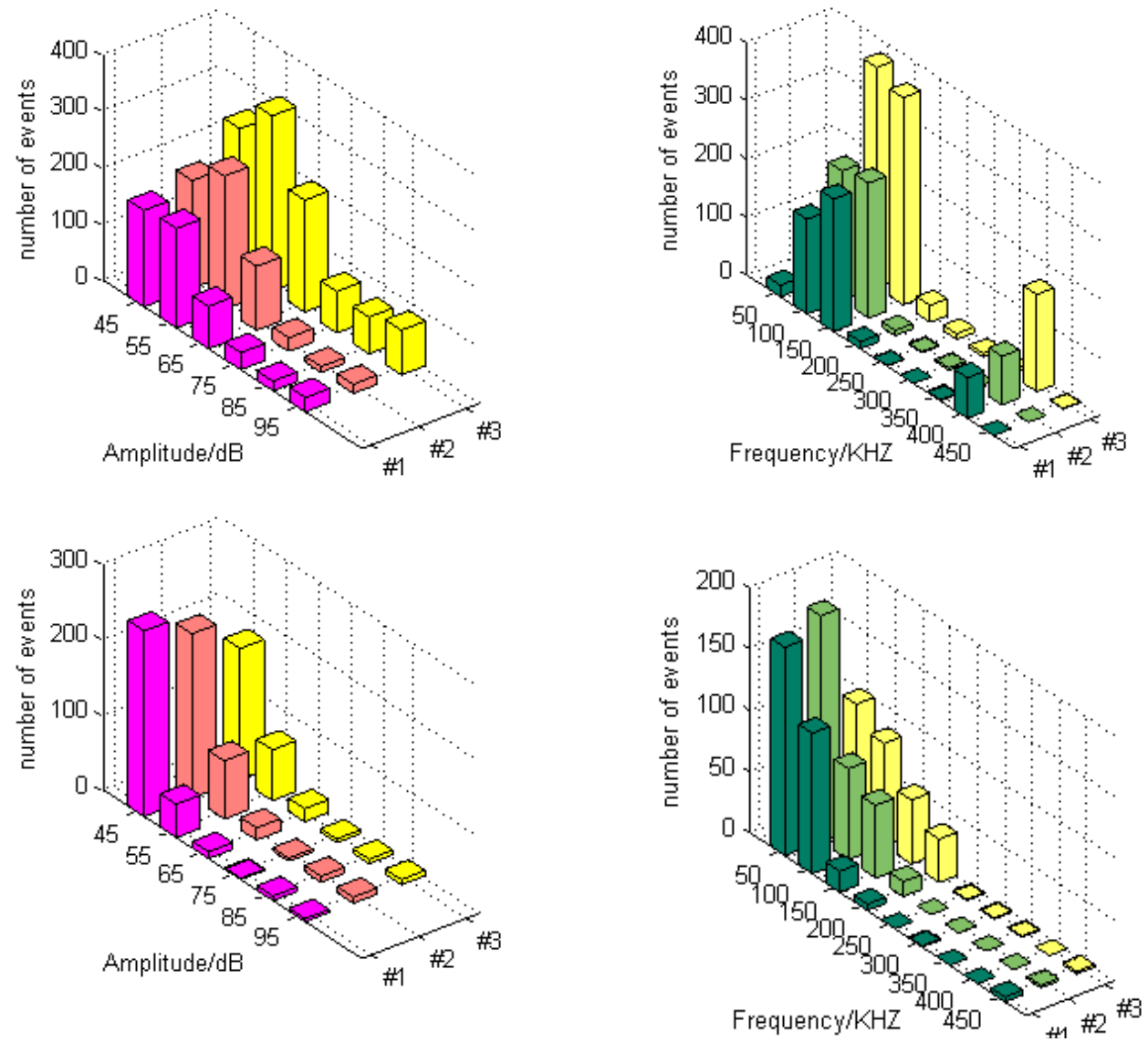

3D
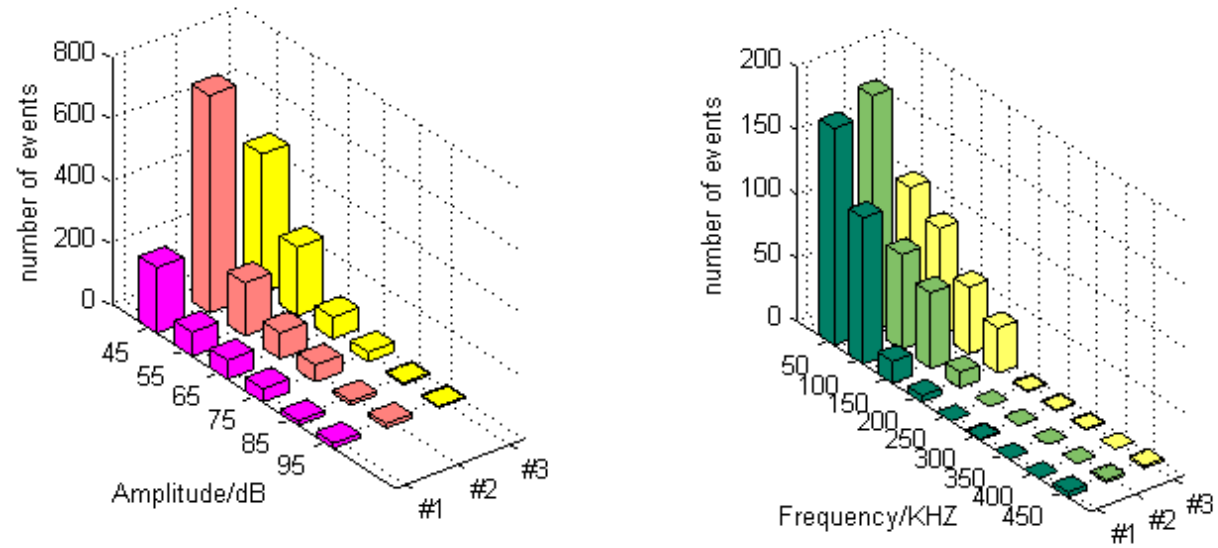

3DF

Fig. 5: Distribution of peak amplitude and peak frequency of the $A E$ events for the individual tests of 2D, 3D-warp (3DW) and 3D-fill (3DF) specimens.

\subsection{Definition of the clusters}

Principle component analysis (PCA) is an orthogonal linear transformation method. It transforms multidimensional $\mathrm{AE}$ data into a set of linearly uncorrelated features in a new coordinate system, which is based on the covariance matrix of the dataset. These 
new features called principal components have the maximum variance amongst all possible transformations of the original coordinate system ${ }^{25}$.

The variance percentage and cumulative variance of each principal $\mathrm{AE}$ component for representative samples are shown in Fig. 6a. The first two principal components can explain more than two-thirds of the total variance, meaning that the two components can visualize the AE data. This is confirmed by Fig. 7, in which clusters are well separated by the projection onto the first two principal components. For different specimen types, the main $\mathrm{AE}$ features corresponding to the first two principal components vary, which can be seen from the coefficients of the principal components in Table 3. The principal components $P d i, i=1 \ldots 4$, which are defined by the principle component analysis (PCA) algorithm are expressed as:

$P d i=\lambda_{1} P A+\lambda_{2} P F+\lambda_{3} R A+\lambda_{4} F C o G, \quad i=1 \ldots 4$

where $\lambda_{i}$ are the principal components coefficients. The coefficients for different specimens are summarized in Table 3, while the contributions of the four $\mathrm{AE}$ parameters to the principal components are shown in Fig. 6b. For 2D specimens, the largest coefficient in the first principal component is the first element, corresponding to the peak amplitude (PA). The second principal component is the peak frequency (PF). The coefficient of the second element, related to the peak frequency, is only slightly lower than the third one (RA value). PF was chosen as the second principal component based on its stronger cluster ability reflected by its high Laplacian score. This score is 0.97 for PF, but only 0.66 for RA. Therefore, peak amplitude and peak frequency can represent $\mathrm{Pd} 1$ and $\mathrm{Pd} 2$ respectively for $2 \mathrm{D}$ samples. The same analysis of the coefficients leads to the conclusion that for 3D samples tested both in warp and fill direction, the peak amplitude and frequency centroid are important for Pd1 and $\mathrm{Pd} 2$. This is evidenced from the clear separation of the AE events by the corresponding AE parameters for 2D and 3D specimens (see Fig. 8). 

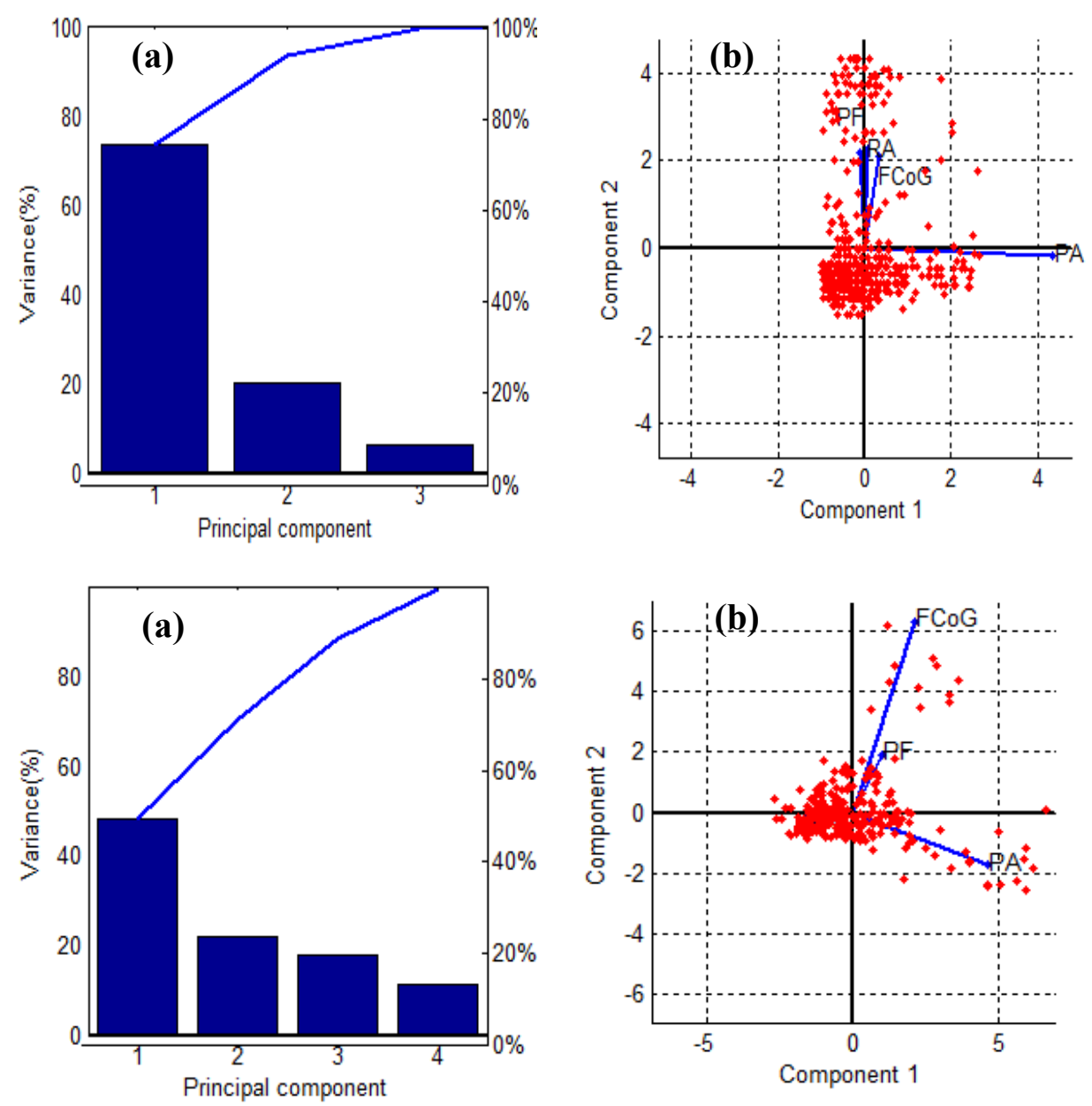

3DW-3
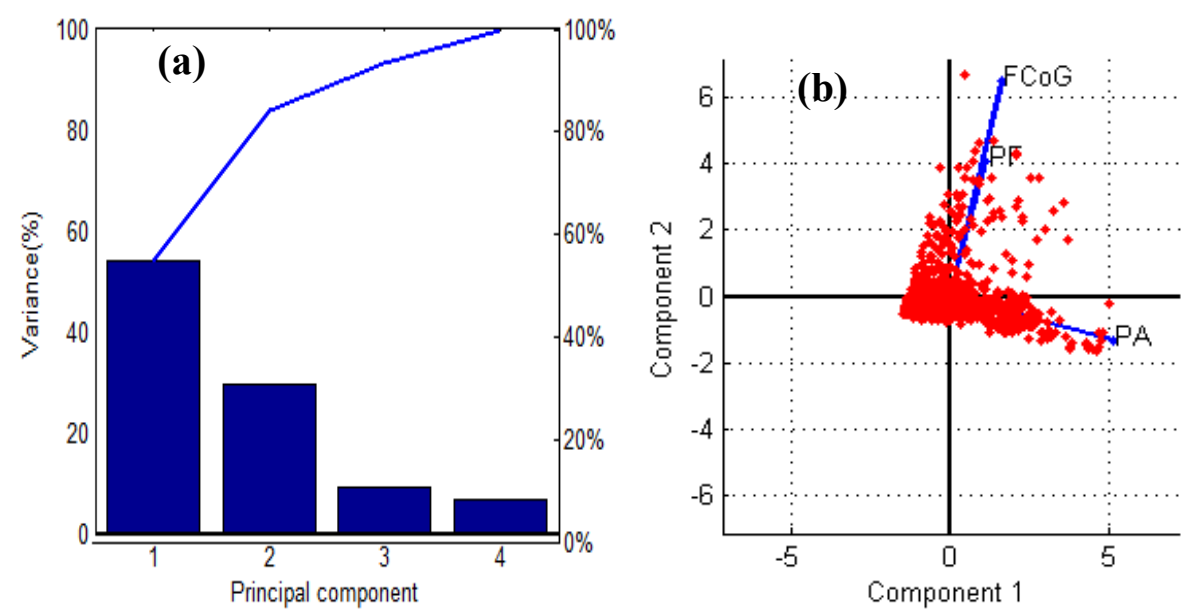

3DF-1

Fig. 6: (a) Variance (bars) and cumulative variance (line) of each principal component for representative samples and (b) component coefficients of $\mathrm{AE}$ parameters for the first two principal components. 

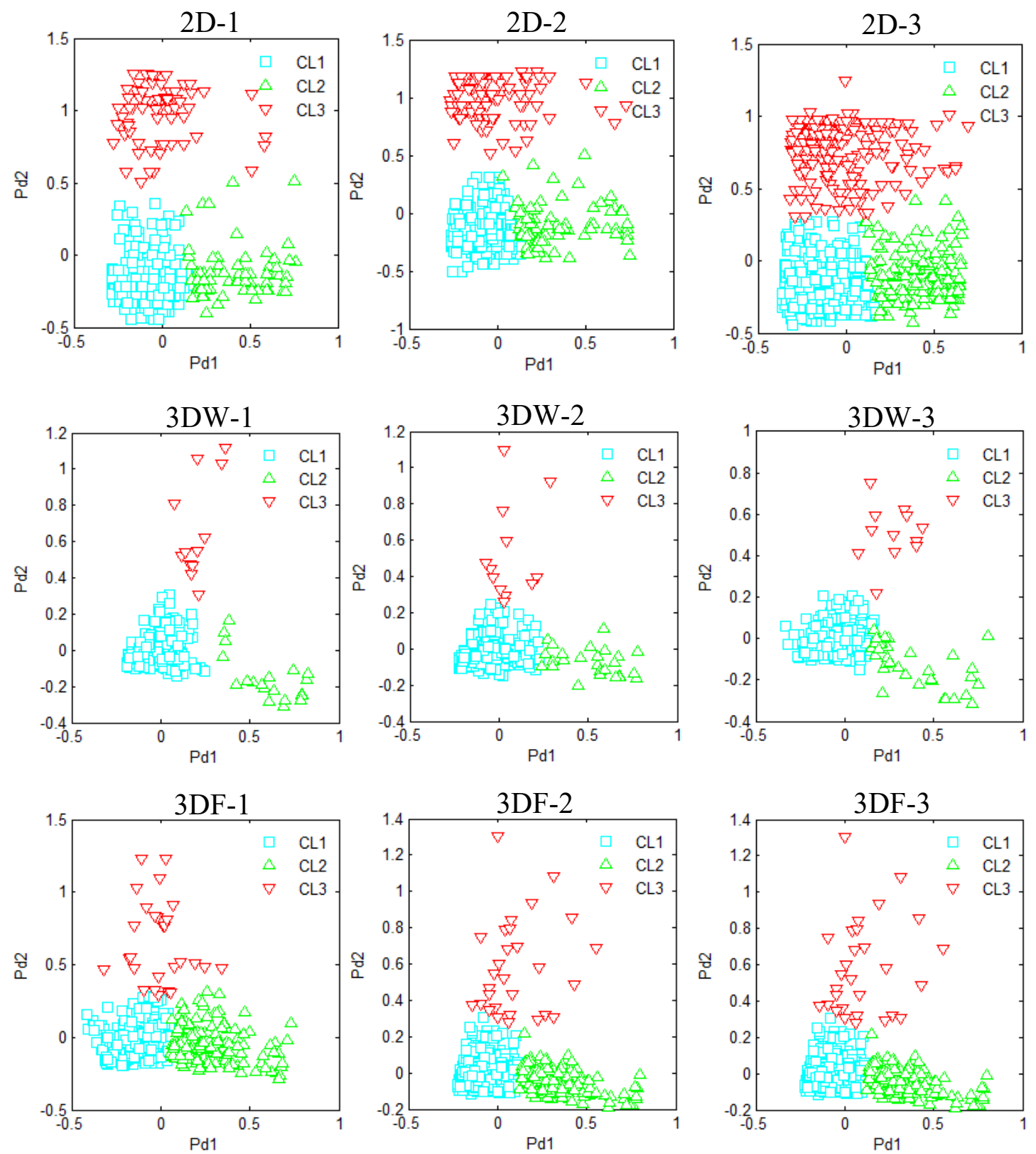

Fig. 7: PCA projection of k-means ++ clustering of the AE events of textile composites to three clusters by the selected AE features.

Table 3 The principal component coefficients for four AE parameters: peak amplitude, peak frequency, RA value and frequency centroid.

\begin{tabular}{ccccccc}
\hline & \multicolumn{2}{c}{$2 \mathrm{D}$} & \multicolumn{2}{c}{$3 \mathrm{DW}$} & \multicolumn{2}{c}{$3 \mathrm{DF}$} \\
& $\mathrm{Pd} 1$ & $\mathrm{Pd} 2$ & $\mathrm{Pd} 1$ & $\mathrm{Pd} 2$ & $\mathrm{Pd} 1$ & $\mathrm{Pd} 2$ \\
\hline$\lambda 1$ & $\mathbf{4 . 3 4}$ & -0.17 & $\mathbf{4 . 6 6}$ & -1.75 & $\mathbf{5 . 1 2}$ & -1.32 \\
$\lambda 2$ & -0.10 & $\mathbf{2 . 1 7}$ & 1.00 & 1.92 & 1.13 & 4.08 \\
$\lambda 3$ & 0.06 & 2.24 & -1.75 & -0.34 & -0.88 & -0.48 \\
$\lambda 4$ & 0.33 & 2.09 & 2.14 & $\mathbf{6 . 3 1}$ & 1.63 & $\mathbf{6 . 4 9}$ \\
\hline
\end{tabular}


Fig. 8 shows the three clusters separated by the amplitude and frequency features, referred to as CL1, CL2 and CL3. The validity of the clusters is can be seen from the Silhouette value and Davies-Bouldin's index in Table 4. For 2D specimens, three clusters are separated by the peak amplitude and peak frequency. CL1 has a low peak amplitude and low peak frequency, in the range of 30-70 dB and 0-300 kHz. CL2 has a high peak amplitude of above $70 \mathrm{~dB}$ and low peak frequency with the same range as CL1. CL3 has broad peak amplitude range from $40 \mathrm{~dB}$ to $100 \mathrm{~dB}$ and a high peak frequency, above $300 \mathrm{kHz}$.
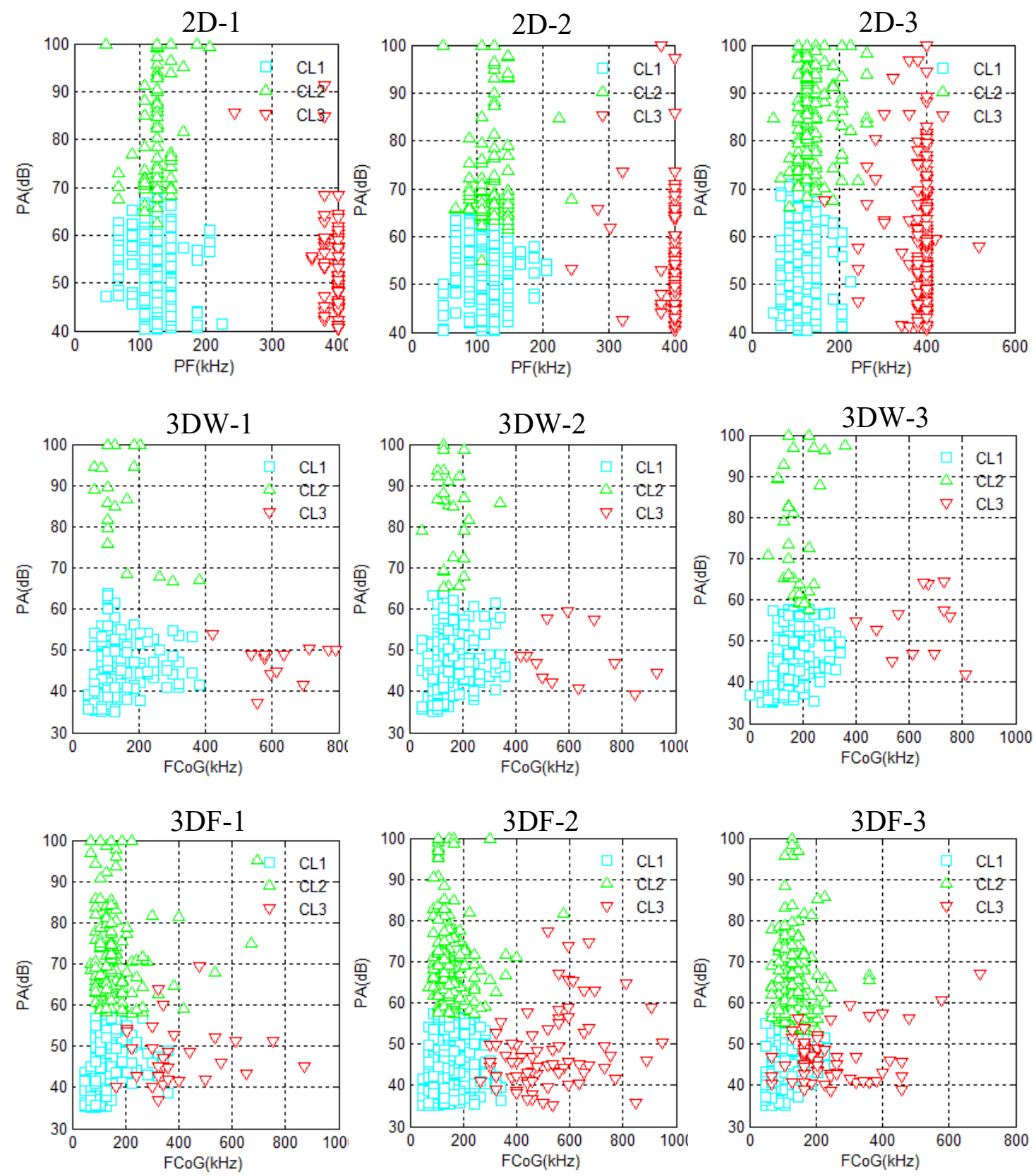

Fig. 8: Cluster results separated by peak amplitude as a function of frequency of the AE events for 
all analyzed specimens to three clusters by the selected $\mathrm{AE}$ features and k-mean++ algorithm.

Table 4: Three groups clustered by k-means++ for all specimens. The SC and DB-index prove the cluster validity.

\begin{tabular}{lccclcc}
\hline Samples & $\begin{array}{l}\text { Number } \\
\text { of events }\end{array}$ & $S C$ & D-B index & \multicolumn{3}{c}{ Percentage of events in each cluster } \\
& & & CL1 & CL2 & CL3 \\
\hline 2D-1 & 519 & 0.71 & 0.75 & 0.71 & 0.15 & 0.14 \\
2D-2 & 588 & 0.64 & 0.84 & 0.76 & 0.15 & 0.07 \\
2D-3 & 588 & 0.72 & 0.69 & 0.62 & 0.19 & 0.19 \\
3DW-1 & 310 & 0.87 & 0.74 & 0.89 & 0.06 & 0.05 \\
3DW-2 & 330 & 0.81 & 0.87 & 0.88 & 0.08 & 0.04 \\
3DW-3 & 275 & 0.66 & 0.92 & 0.81 & 0.14 & 0.04 \\
3DF-1 & 422 & 0.63 & 1.17 & 0.57 & 0.35 & 0.07 \\
3DF-2 & 1035 & 0.73 & 0.97 & 0.75 & 0.17 & 0.08 \\
3DF-3 & 778 & 0.58 & 1.26 & 0.71 & 0.26 & 0.03 \\
\hline
\end{tabular}

For 3D woven specimens in warp direction (3DW), the three clusters are separated by the peak amplitude and frequency centroid. These clusters have the same structure as for the 2D samples: three clusters representing AE events with low amplitude - low frequency; high amplitude - low frequency, and high frequency (irrespective of amplitude). CL1 has a peak amplitude of 30-60 dB and a frequency of 0-400 kHz. CL2 has a higher peak amplitude and a lower frequency compared to CL1. The frequency range of CL3 is above $400 \mathrm{kHz}$.

For 3D woven specimens in fill direction (3DF), there is an overlap of the three clusters, especially for CL1 and CL3. On the whole, CL1 and CL2 have the same cluster distribution as 3DW: the peak amplitude range and frequency range is 30-60 $\mathrm{dB}$ and $0-400 \mathrm{kHz}$ for CL1, while it is $55-100 \mathrm{~dB}$ and $0-400 \mathrm{kHz}$ for CL2. CL3 on the other hand has a broad range of amplitude and frequency, 30-90 dB and above 400 $\mathrm{kHz}$, and there is an overlap in the frequency from $200 \mathrm{kHz}$ to $400 \mathrm{kHz}$ for CL1 and CL3.

The clusters CL1-CL3 are labelled as CL-AlFl, CL-AhF1 and CL-AbFh to facilitate distinguishing and discussing the clusters for all $2 \mathrm{D}$ and $3 \mathrm{D}$ composites. ' 1 ', ' $h$ ', ' $b$ ' are short for "low", "high" and "broad" respectively. 'A' relates to peak amplitude and 'F' corresponds to frequency features. CL-AlFl therefore represents a cluster with a low amplitude and low frequency, where frequency can either represent PF or FCoG. CLAhFl represents a cluster with a high amplitude and low frequency, whereas CL-AbFh stands for broad amplitude and high frequency.

\subsection{Discussion of the cluster analysis results}

The clusters for both 2D and 3D carbon/epoxy composites are summarized in Table 5. For $2 \mathrm{D}$ specimens, CL-AlFl has peak amplitudes below $70 \mathrm{~dB}$, and peak frequencies below $300 \mathrm{kHz}$. The CL-AhFl peak amplitude is above $70 \mathrm{~dB}$. CL-AbFh has a broad peak amplitude ranging from $30 \mathrm{~dB}$ to $90 \mathrm{~dB}$, and a peak frequency above $300 \mathrm{kHz}$. 
For the 3D specimens, CL-AlF1 has a peak amplitude below $60 \pm 5 \mathrm{~dB}$, and a frequency centroid below $400 \mathrm{kHz}$. CL-AhFl has a peak amplitude above $60 \pm 5 \mathrm{~dB}$, whereas CLAbFh has a frequency centroid of above $400 \mathrm{kHz}$ and $30-90 \mathrm{~dB}$ peak amplitude. Therefore, the cluster bounds for $2 \mathrm{D}$ are a peak amplitude of $70 \mathrm{~dB}$ and a peak frequency of $300 \mathrm{kHz}$. For $3 \mathrm{D}$, these bounds are a peak amplitude of $60 \pm 5 \mathrm{~dB}$, and a frequency centroid of $400 \mathrm{kHz}$.

Table 5: Summary of the three clusters for 2D and 3D carbon/epoxy specimens.

\begin{tabular}{ccccccc}
\hline Clusters & \multicolumn{2}{c}{ 2D carbon/epoxy } & \multicolumn{2}{c}{ 3D carbon/epoxy } & \multicolumn{2}{c}{ 2D\&3D glass/epoxy ${ }^{21}$} \\
& PA $(\mathrm{dB})$ & $\mathrm{PF}(\mathrm{kHz})$ & $\mathrm{PA}(\mathrm{dB})$ & $\mathrm{FCoG}(\mathrm{kHz})$ & $\mathrm{PA}(\mathrm{dB})$ & $\mathrm{PF}(\mathrm{kHz})$ \\
\hline CL-AlFl & $\leq 70$ & $<300$ & $<60 \pm 5$ & $<400$ & $\leq 60$ & $\leq 150$ \\
CL-AhFl & $>\mathbf{7 0}$ & $<\mathbf{3 0 0}$ & $>\mathbf{6 0} \pm \mathbf{5}$ & $<\mathbf{4 0 0}$ & $>\mathbf{6 0}$ & $\leq \mathbf{1 5 0}$ \\
$\mathrm{CL}-\mathrm{AbFh}$ & $30 \ldots 90$ & $\geq 300$ & $30 \ldots 90$ & $\geq 400$ & $35 \ldots 90$ & $>150$ \\
\hline
\end{tabular}

For the 2D and 3D carbon/epoxy composites, $\mathrm{AE}$ events are classified by either peak frequency or frequency centroid. In the 2D specimens, transverse matrix cracks dominate the initiation and propagation of damage, leading to appearance of local delaminations between the woven plies (see Fig. 1c) ${ }^{3}$. In the $3 \mathrm{D}$ specimens the damage starts in the form of boundary cracks and Z-yarn cracks, whith further development of local debondings between the warp and weft yarns (see Fig. 1d) ${ }^{4}$. It is possible that this difference in damage morphology causes the different $\mathrm{AE}$ features in the clusters. One can speculate that relatively large interlayer delaminations in 2D specimens, which are larger than debondings between warp and weft in 3D specimens, can be expected to produce AE events with larger amplitude.

Table 5 compares cluster bounds for 2D and 3D composites reinforced with glass fibers $^{21}$ and carbon fibers. The cluster bounds of $2 \mathrm{D}$ and $3 \mathrm{D}$ glass/epoxy are a peak amplitude of $60 \mathrm{~dB}$ and a peak frequency of $150 \mathrm{kHz}$. 2D twill 2/2 carbon/epoxy composites have higher cluster bounds, peak amplitude with $70 \mathrm{~dB}$ and peak frequency with $300 \mathrm{kHz}$, compared to 2D and 3D glass/epoxy. For 3D carbon/epoxy specimens, the cluster bound of peak amplitude is similar with glass/epoxy, but the frequency bound is $400 \mathrm{kHz}$, which is higher than that of glass/epoxy with $150 \mathrm{kHz}$.

To summarize, the cluster bounds of amplitude and frequency for carbon fiber reinforced composites are higher than the ones for the glass/epoxy composites. A possible explanation is the higher stiffness of carbon fiber, which may lead to a higher amplitude and frequency of the AE signals.

Different frequency descriptors can be found for the different studied composites. Considering the signal amplitude and frequency separately does not guarantee distinct boundaries between the event groups. Therefore, it is advisable to perform a full cluster analysis to achieve a reliable classification of the AE events.

Typical signals for the three clusters for 2D and 3D carbon/epoxy composites are shown in Fig. 9. The signal spectrum shows that 2D specimens have broad frequency range for the first two clusters: CL-AlFl and CL-AhFl. The difference of the two 
clusters is that only the energy of CL-AhFl is higher than CL-AlFl. 3DW and 3DF specimens have similar acoustic emission signal spectrums for the three clusters. But CL-AlFl of 3D specimens has a broad frequency range, whereas events in CL-AhFl of 3D specimens are mainly in the frequency range of $0-200 \mathrm{kHz}$. For the third cluster $\mathrm{CL}-\mathrm{AbFh}$, the peak frequency is above $400 \mathrm{kHz}$ for $2 \mathrm{D}$. In the spectrum for $3 \mathrm{D}$, it can be seen that the ratio of FFT magnitude to maximum magnitude is higher than that of CL-AhFl for frequencies above $200 \mathrm{kHz}$.
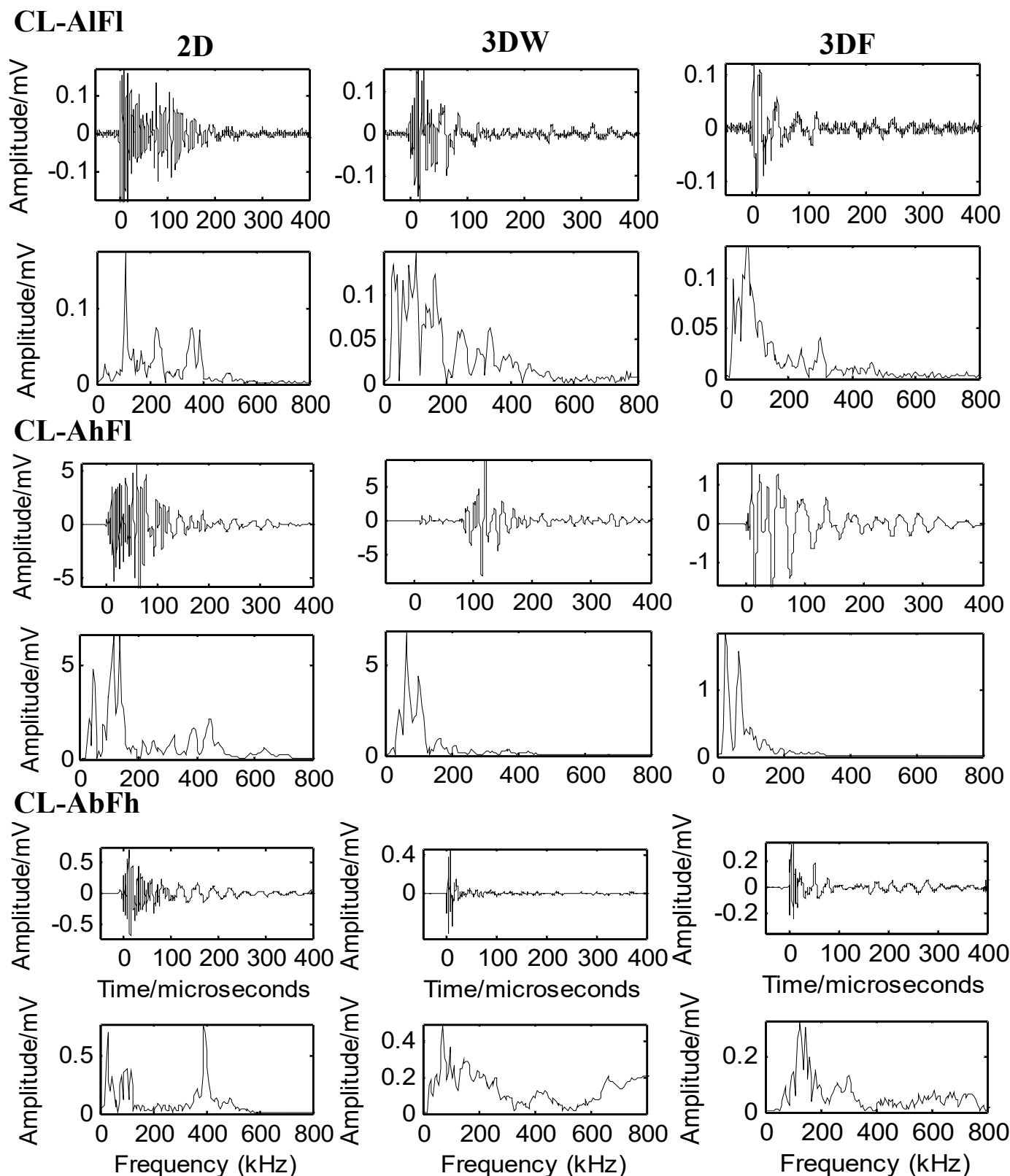

Time/microseconds

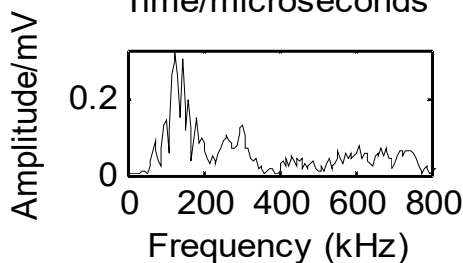

Fig. 9: Typical AE signals and corresponding frequency spectrums for three clusters CL-AIFl, CLAhFl and CL-AbFh for 2D, 3DW and 3DF carbon/epoxy composites. 


\section{High frequency events (CL-AbFh) and statistics of the fiber failure}

The yarns in the studied composite materials have a low crimp: below $1 \%$ in the $2 \mathrm{D}$ woven laminates ${ }^{3}$ and even below $0.1 \%$ in the $3 \mathrm{D}$ non-crimp orthogonally woven fabrics ${ }^{26}$. The fiber failure is therefore controlled by the strain applied to the composite. This creates the possibility to compare the statistics of the fiber failure with the number of $\mathrm{AE}$ events in the high frequency cluster $\mathrm{CL}-\mathrm{AbFh}$. If such a comparison shows significant similarities, then it can be considered as a validation of the connection of the high frequency $\mathrm{AE}$ events with fiber failure. This connection is generally accepted in literature ${ }^{11,}{ }^{27}$. However, a preliminary Weibull-based estimation $^{5}$ has shown large discrepancies between the predicted number of fiber breaks and the number of registered high frequency AE events. Weibull estimations of the probability of individual fiber breakage indicated a much earlier start and much larger number of fiber breaks than the measurements from $\mathrm{AE}$ events. Here, two possible hypotheses are explored, which may resolve this discrepancy: (1) influence of the fiber misalignment on their breakage and (2) simultaneous fiber breakage in a bundle.

\subsection{Misalignment of the fibers}

Misalignment of the fibers in the yarns / fiber bundles was estimated using a structure tensor analysis ${ }^{28}$ of micro-CT images of the composites, shown in Fig.1. The misalignment angle of the fibers (difference between the direction of the fiber and the direction of the center line of the yarn) was found to follow a Gaussian distribution, with an average of 0 and standard deviation of $2.5^{\circ}$. Simple geometrical considerations relate the strain in the fiber $\varepsilon$, inclined by an angle $\theta$, to the elongation of the yarn $\varepsilon$ as the following equation:

$\varepsilon_{f}(\varepsilon, \theta)=\max \left(0, \frac{\sqrt{(1+\varepsilon)^{2}+v^{2} \operatorname{tg}^{2} \theta}-\sqrt{1+\operatorname{tg}^{2} \theta}}{\sqrt{1+\operatorname{tg}^{2} \theta}}\right)$,

where $v$ is Poisson coefficient of the impregnated yarn, estimated as $v=0.4$. Then, the number of broken fibers $N$ in a bundle under tensile strain $\varepsilon$ can be estimated as:

$N(\varepsilon)=N_{\Sigma} \int_{0}^{\pi} \psi(\theta) P\left(\varepsilon_{f}(\varepsilon, \theta)\right) d \theta$

where $N_{\Sigma}$ is the total number of fibers in the bundle, $\psi(\theta)$ is the distribution of the misalignment angles $\theta, P\left(\varepsilon_{f}\right)$ is the probability of the fiber breakage defined by Weibull distribution.

This analysis found only a negligible effect of the misalignment on the number of fiber breaks, compared to the case without misalignment (assuming $\psi(\theta)=\delta(\theta)$ ). After the misalignment was taken into account, the estimation of the number of broken fibers 
changed only by $5 \ldots 10 \%$ for Weibull shape parameters between 6 and 8 . Therefore, the fiber misalignment cannot explain the discrepancy between the Weibull-predicted fiber breakage count and the high frequency AE registrations, and other explanations should be explored.

\subsection{Simultaneous fiber breakage}

The second hypothesis for explaining the discrepancy between the number of Weibullpredicted fiber breaks and the high frequency AE registrations is the possible weakness of an $\mathrm{AE}$ event generated by an isolated fiber breakage. It is hypothesized that simultaneous breakage of several fibers is needed to create a noticeable AE event. To evaluate this hypothesis, the model of fiber breakage in a fiber bundle, proposed by Swolfs et al. is used. This model has been extensively described in literature ${ }^{16-20,30}$. This description will not be repeated here, but the main points and input parameters will be highlighted.

The model considers an impregnated bundle of parallel fibers. Unfortunately, due to high computational costs, it is impossible to model the full specimen size studied in the experiments. Instead, a single $6 \mathrm{~K}$ yarn with a $10 \mathrm{~mm}$ length was modelled. In the model, each fiber is divided into fiber elements with a length of $3.5 \mu \mathrm{m}$, giving a total of 2857 elements per fiber. A strength value is assigned to each element according to the Weibull distribution. The applied longitudinal strain on the bundle of fibers is gradually incremented. At each strain increment, fiber failure is checked by comparing element stress with element strength. If a fiber element fails, then this element locally loses its load transfer capability and the stress on the nearby fiber elements increases. This stress redistribution is taken into account by the model using the finite element (FE) data in literature ${ }^{16,17}$. Fiber element failure is then checked again until no new elements break within the same strain increment. If no new element failures are detected, then the model increments the strain. This is repeated until final failure is detected.

The procedure allows the groups of fiber breaks to be tracked. Two fiber breaks are part of the same group if (1) the lateral distance between their fiber centers is smaller than 4 fiber radiuses, and (2) the axial distance between both breaks is less than 10 fiber radiuses. This definition corresponds to the dimensions of the zone where the stress concentrations are significant. Simultaneous fiber breakage is defined as two or more fiber breaks that fail within the same strain increment and are part of the same group of fiber breaks.

The model parameters were chosen in such a way that they can represent the fiber bundles in both 2D and 3D materials in an average way. The axial fiber stiffness was $230 \mathrm{GPa}$, and the full engineering constants for the fibers can be found in Swolfs et al. ${ }^{30}$. The matrix stiffness was $3 \mathrm{GPa}$. The fiber volume fraction was $70 \%$, which corresponds to the measured fiber volume fractions inside yarns ${ }^{25}$. The Weibull distribution $P_{f}$ is used to assign a strength value to each fiber element ${ }^{29}$ : 
$P_{f}=1-\exp \left[-\left(\frac{L}{L_{0}}\right) \cdot\left(\frac{\sigma_{f}}{\sigma_{0}}\right)^{m}\right]$,

where $\sigma_{f}$ is the fiber strength, $\sigma_{0}$ is the Weibull scale parameters, $L$ is the element length, $L_{0}$ is the reference gauge length, and $m$ is the Weibull shape parameter or modulus. The Weibull modulus was either 5 or 8 , which are typical values for carbon fiber ${ }^{31}$. The Weibull scale parameter was adapted to obtain a composite failure strain of $1.8 \%$, which corresponds to the failure strain from the carbon fiber datasheets. The reference gauge length $L_{0}$ was $10 \mathrm{~mm}$. A total of 100 simulations were performed for both Weibull moduli, and the number of fiber breaks and groups of fiber breaks were averaged. This average is then multiplied by 612 . This factor is obtained from the ratio of the volume of fibers in the warp direction of the $2 \mathrm{D}$ weave over the volume of fibers in the strength model. This multiplication factor was chosen because it lies in between the factors 1034 and 571 for the 3D weave in warp and fill direction respectively. If one of these limiting values is chosen, then the results are scaled differently, but their interpretation would remain the same.

Fig. 10 presents the results of the simultaneous fiber breaks and compares it with the cluster analysis results. The results agree reasonably well with the cluster analysis results, especially compared to the discrepancies with the analysis presented in Lomov et al. ${ }^{5}$, which roughly corresponds to the "all breaks" curve in Fig. 10. The agreement seems to be better for $m=8$ than for $m=5$. While this does not prove that AE is unable to detect single fiber breaks, it does shed a new light on what AE can detect. For the total number of fiber breaks, the cluster analysis results yield much lower values than the Weibull prediction. This discrepancy exists despite existing evidence of a one-toone correlation between the number of $\mathrm{AE}$ events and the number of fiber breaks observed by the polarized light microscope in the single fiber tensile test ${ }^{26,32}$. Further experimental work is needed to confirm that $\mathrm{AE}$ indeed only detects simultaneous fiber breaks in fiber-reinforced polymer composites. 


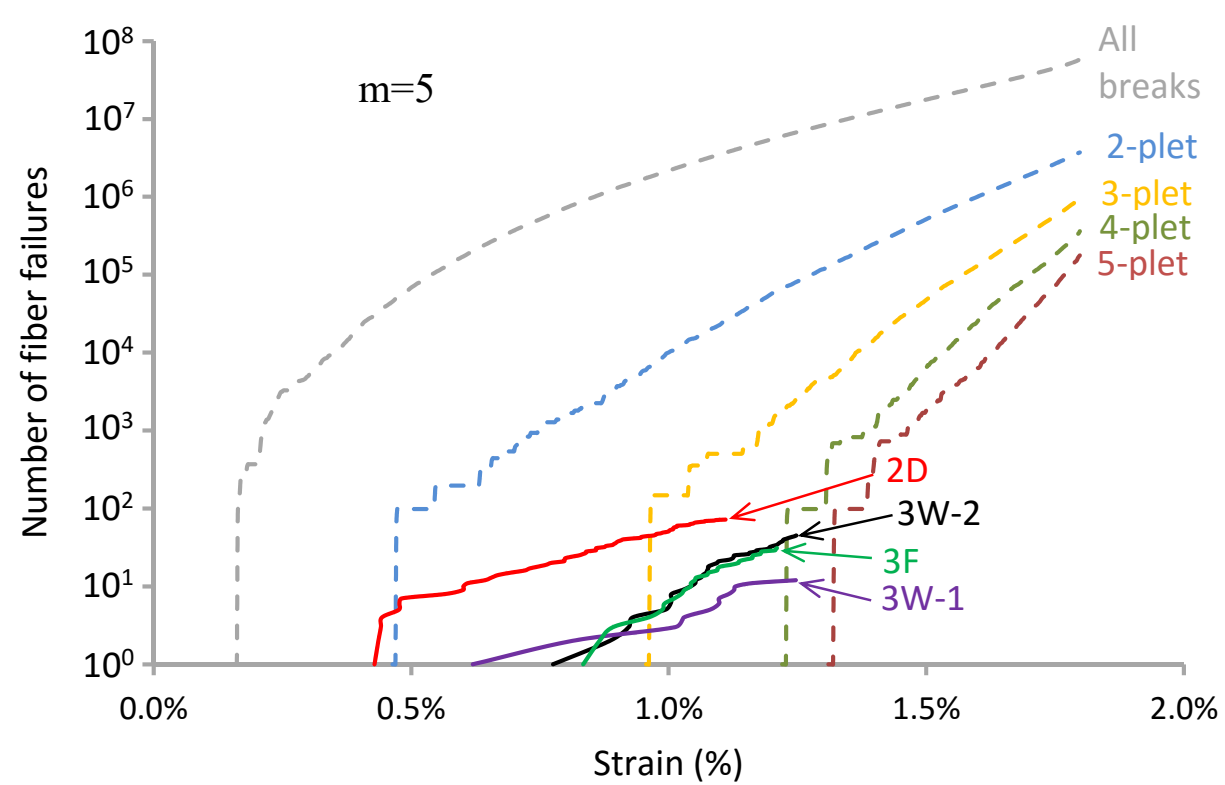

(a)

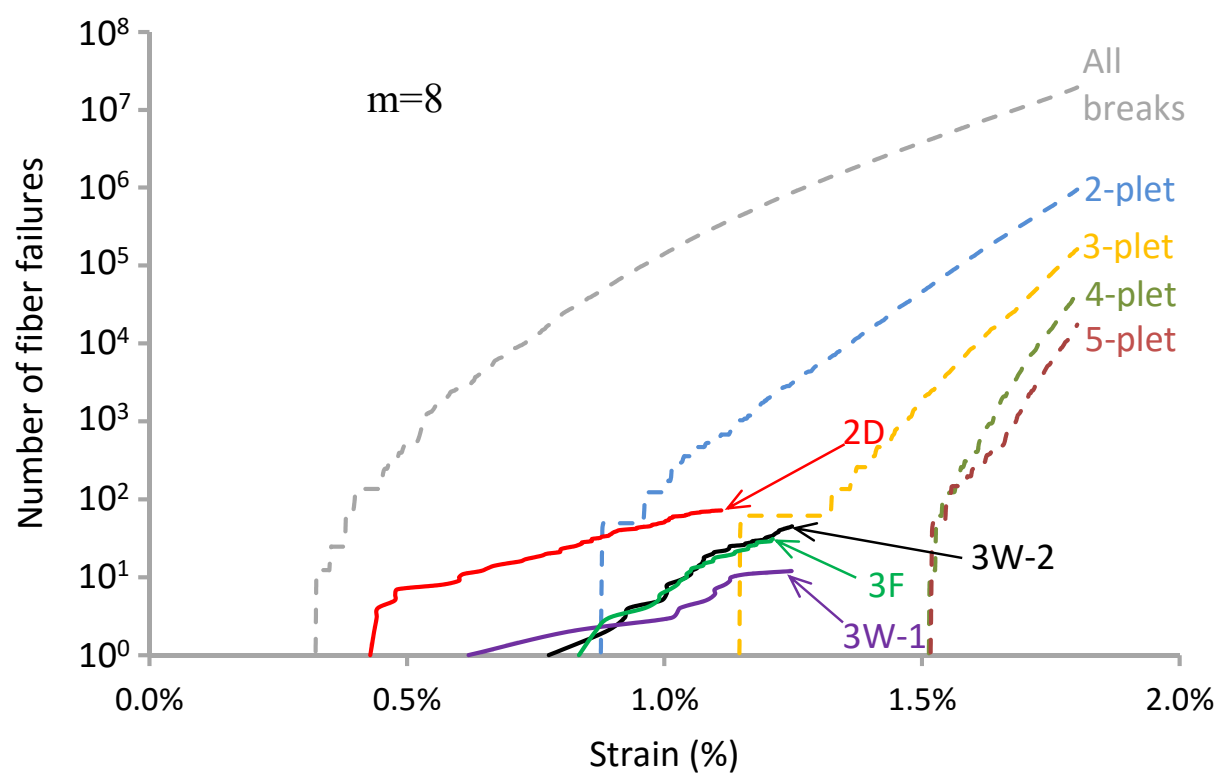

(b)

Fig. 10: Comparison between the number of high frequency $\mathrm{AE}$ events and the average number of grouped fiber failures that occurred simultaneously in the strength model: (a) for a Weibull modulus of 5, and (b) for a Weibull modulus of 8. An i-plet is defined as a group of "i" fiber breaks near each other that fail within the same strain increment. The "All breaks" data does not satisfy this definition, but is added nonetheless to facilitate comparison.

\section{Conclusions}

In this study, unsupervised cluster analysis is performed for AE registration of $2 \mathrm{D}$ and 3D carbon/epoxy woven composites during tension loading. Peak amplitude and 
frequency features were found to be the most relevant for the cluster analysis. Different frequency features were however found to be crucial for different specimens. For example, the peak frequency was the most relevant frequency feature for $2 \mathrm{D}$ woven, while this was the frequency centroid for 3D woven composites. Therefore it is advisable to perform a full cluster analysis to achieve a reliable classification of the $\mathrm{AE}$ events.

The AE cluster structure for carbon/epoxy woven composites is the same as for their previously studied ${ }^{21}$ glass/epoxy counterparts. The only difference is that the cluster bounds of amplitude and frequency for the carbon/epoxy composites are higher than for the glass/epoxy.

The development of high frequency AE events under increasing tensile loading and predictions of simultaneous fiber breakage based on Weibull statistics were compared. This comparison suggested that the $\mathrm{AE}$ events in the high frequency cluster correspond to the simultaneous breakage of fibers in the bundles. This gives additional grounds for the hypothesis that high frequency AE events represent fiber breakage.

\section{Acknowledgments}

The research visit of L. Li to KU Leuven was funded by Chinese Scholarship Council and partially supported by FWO project G.0354.09. The raw AE data used in the present study and damage images in Fig. 1 were acquired by M. Karahan ${ }^{4}$ and N. De Greef $^{3}$. The authors thank the Agency for Innovation by Science and Technology in Flanders (IWT) for a grant given to Y. Swolfs. The authors are grateful to L. Gorbatikh for the discussion of the presented results.

The X-ray computed tomography images have been made on the X-ray computed tomography facilities at the KU Leuven, financed by the Hercules Foundation (project AKUL 09/001: Micro- and nano-CT for the hierarchical analysis of materials), and maintained under supervision of Prof M. Wevers. The authors would like to thank A.E. Bogdanovich (NCSU, USA) for the provision of the material and for useful discussions of the material's internal structure. The help with Vallen AE system of Johan Vanhulst and useful discussions with Dr. Sergey Ivanov are acknowledged with gratitude.

\section{References}

1. Bourchak M, Farrow I, Bond I, Rowland C and Menan F. Acoustic emission energy as a fatigue damage parameter for CFRP composites. Int J Fatigue 2007; 29: 457-470.

2. Bourchak M, Khan A, Badr SA and Harasani W. Acoustic emission characterization of matrix damage initiation in woven CFRP composites. Mater Sci Appl 2013; 4: 509515.

3. De Greef N, Gorbatikh L, Godara A, Mezzo L, Lomov SV and Verpoest I. The effect of carbon nanotubes on the damage development in carbon fiber/epoxy composites. Carbon 2011; 49: 4650-4664.

4. Bogdanovich AE, Karahan M, Lomov SV and Verpoest I. Quasi-static tensile behavior and damage of carbon/epoxy composite reinforced with 3D non-crimp orthogonal woven fabric. Mech Mater 2013; 62: 14-31. 
5. Lomov S, Karahan M, Bogdanovich A and Verpoest I. Monitoring of acoustic emission damage during tensile loading of 3D woven carbon/epoxy composites. Text Res $J$ 2014; 84: 1373-1384.

6. Karimi NZ, Minak G and Kianfar P. Analysis of damage mechanisms in drilling of composite materials by acoustic emission. Compos Struct 2015; 131: 107-114.

7. Fotouhi M, Saeedifar M, Sadeghi S, Najafabadi MA, and Minak G. Investigation of the damage mechanisms for mode I delamination growth in foam core sandwich composites using acoustic emission. Struct Health Monit 2015; 14: 265-280.

8. Lomov SV, Ivanov D, Truong T, et al. Experimental methodology of study of damage initiation and development in textile composites in uniaxial tensile test. Compos Sci Technol 2008; 68: 2340-2349.

9. Sause M, Gribov A, Unwin A and Horn S. Pattern recognition approach to identify natural clusters of acoustic emission signals. Pattern Recogn Lett 2012; 33: 17-23.

10. Sause M, Müller T, Horoschenkoff A and Horn S. Quantification of failure mechanisms in mode-I loading of fiber reinforced plastics utilizing acoustic emission analysis. Compos Sci Technol 2012; 72: 167-174.

11. Gutkin R, Green C, Vangrattanachai S, Pinho S, Robinson P and Curtis P. On acoustic emission for failure investigation in CFRP: Pattern recognition and peak frequency analyses. Mech Syst Signal Pr 2011; 25: 1393-1407.

12. Valentin D, Bonniau P and Bunsell A. Failure mechanism discrimination in carbon fibre-reinforced epoxy composites. Compos 1983; 14: 345-351.

13. Liu P, Chu J, Liu Y and Zheng J. A study on the failure mechanisms of carbon fiber/epoxy composite laminates using acoustic emission. Mater Design 2012; 37: 228-235.

14. Berthelot J and Rhazi J. Acoustic emission in carbon fibre composites. Compos Sci Technol 1990; 37: 411-428.

15. De Groot PJ, Wijnen PA and Janssen RB. Real-time frequency determination of acoustic emission for different fracture mechanisms in carbon/epoxy composites. Compos Sci Technol 1995; 55: 405-412.

16. Swolfs Y, Gorbatikh L, Romanov V, Orlova S, Lomov SV and Verpoest I. Stress concentrations in an impregnated fibre bundle with random fibre packing. Compos Sci Technol 2013; 74: 113-120.

17. Swolfs Y, Gorbatikh L and Verpoest I. Stress concentrations in hybrid unidirectional fibre-reinforced composites with random fibre packings. Compos Sci Technol 2013; 85: 10-16.

18. Swolfs Y, McMeeking R, Verpoest I, Gorbatikh L. Matrix cracks around fibre breaks and their effect on stress redistribution and failure development in unidirectional composites. Compos Sci Technol 2015; 108:16-22.

19. Swolfs Y, McMeeking R, Verpoest I, Gorbatikh L. Initial failure development in unidirectional hybrid composites revealed through modelling. Compos Part A: Appl S 2014; 69: 279-287.

20. Swolfs Y, Morton H, Scott AE, Gorbatikh L, Reed PAS, Sinclair I. Synchrotron radiation computed tomography for experimental validation of a tensile strength model for unidirectional fibre-reinforced composites. Compos Part A: Appl S 2014; DOI: 10.1016/j.compositesa.2015.06.018. 
21. Li L, Lomov SV, Yan X and Carvelli V. Cluster analysis of acoustic emission signals for 2D and 3D woven glass/epoxy composites. Compos Struct 2014; 116: 286 299.

22. Maillet E, Baker C, Morscher GN, Pujar VV, and Lemanski JR. Feasibility and limitations of damage identification in composite materials using acoustic emission. Compos Part A: Appl S 2015; 75: 77-83.

23. Ono $\mathrm{K}$ and $\mathrm{Cho} \mathrm{H}$. Experimental transfer functions of practical acoustic emisssion sensors. In: 28 European Conference of AE Testing, Cracow UT, 2008, pp. 25-30.

24. He X, Cai D and Niyogi P. Laplacian score for feature selection. Advances in neural information processing systems. Vancouver, BC, Canada, 5 - 8 December, 2005, pp. 507-514.

25. Jolliffe I. Principal component analysis. Wiley Online Library, 2005.

26. Karahan M, Lomov SV, Bogdanovich AE, Mungalov D and Verpoest I. Internal geometry evaluation of non-crimp 3D orthogonal woven carbon fabric composite. Compos Part A: Appl S 2010; 41: 1301-1311.

27. Giordano M, Calabro A, Esposito C, D'Amore A and Nicolais L. An acousticemission characterization of the failure modes in polymer-composite materials. Compos Sci Technol 1998; 58: 1923-1928.

28. Straumit I, Lomov, S.V. Wevers, M. Quantification of the internal structure and the automatic generation of voxel models of textile composites from X-ray computed tomography data. Compos Part A: Appl S 2015; 69:150-158.

29. Swolfs Y, Verpoest I and Gorbatikh L. Issues in strength models for unidirectional fibre-reinforced composites. Compos Sci Technol 2015; 114: 42-49.

30. Swolfs Y, Gorbatikh L, Romanov V, Orlova S, Lomov SV and Verpoest I. Stress concentrations in an impregnated fibre bundle with random fibre packing. Compos Sci Technol 2013; 74: 113-120.

31. Naito K. Tensile properties of polyacrylonitrile- and pitch-based hybrid carbon fiber/polyimide composites with some nanoparticles in the matrix. J Mater Sci Lett 2013; 48: 4163-4176.

32. Godin N, Huguet S, Gaertner R and Salmon L. Clustering of acoustic emission signals collected during tensile tests on unidirectional glass/polyester composite using supervised and unsupervised classifiers. NDT \& E Int 2004; 37: 253-264. 